\title{
IMPACT OF VENTILATOR-Associated PNEUMONIA ON Resource Utilization and Patient Outcome
}

\author{
Stéphane Hugonnet, MD, MSc; Philippe Eggimann, MD; François Borst, MD; Patrice Maricot; Jean-Claude Chevrolet, MD;
} Didier Pittet, MD, MS

\begin{abstract}
OBJECTIVE: To assess the effect of ventilator-associated pneumonia on resource utilization, morbidity, and mortality.

DESIGN: Retrospective matched cohort study based on prospectively collected data.

SETTING: Medical intensive care unit of a university teaching hospital.

PATIENTS: Case-patients were all patients receiving mechanical ventilation for 48 hours or more who experienced an episode of ventilator-associated pneumonia. Control-patients were matched for number of discharge diagnoses, duration of mechanical support before the onset of pneumonia among casepatients, age, admission diagnosis, gender, and study period.

RESULTS: One hundred six cases of ventilator-associated pneumonia were identified in 452 patients receiving mechani-
\end{abstract}

Healthcare-associated infection is the leading preventable adverse event among hospitalized patients, affecting 2 million individuals and costing $\$ 10$ to $\$ 20$ billion every year in the United States. ${ }^{1,2}$ Critically ill patients represent a large part of this burden and pneumonia is known to be the leading infection in this population. . $^{3,4}$ Ventilator-associated pneumonia (VAP) occurs in approximately $25 \%$ of patients receiving mechanical ventilation at a rate of 4 to 25 episodes per 1,000 ventilator-days ${ }^{5-10}$ and has a crude mortality rate ranging from $20 \%$ to $70 \%{ }^{11-15}$

The impact of VAP on mortality remains controversial; some studies found that VAP had a significant excess mortality, ${ }^{3,12,16,17}$ whereas others did not. ${ }^{14,15,18-20}$ Although mortality is an important element that will help evaluate the impact of prevention efforts, it might not be the best outcome indicator because (1) attributable mortality might be marginal among patients receiving ventilation who are already extremely ill and at high risk of death and (2) it does not capture what happens in patients who survive an episode of VAP. Length of intensive care unit cal ventilation. The matching procedure selected 97 pairs. Length of stay in the intensive care unit and duration of mechanical ventilation were greater among case-patients by a mean of 7.2 days $(P<.001)$ and 5.1 days $(P<.001)$, respectively. Median costs were $\$ 24,727$ (interquartile range, $\$ 18,348$ to $\$ 39,703$ ) among casepatients and $\$ 17,438$ (interquartile range, $\$ 12,261$ to $\$ 24,226$ ) among control-patients $(P<.001)$. The attributable mortality rate was $7.3 \%(P=.26)$. The attributable extra hospital stay was 10 days with an extra cost of $\$ 15,986$ per episode of pneumonia.

CONCLUSION: Ventilator-associated pneumonia negatively affects patient outcome and represents a significant burden on intensive care unit and hospital resources (Infect Control Hosp Epidemiol 2004;25:1090-1096).
(ICU) or hospital stay has been shown to be greater among patients with VAP. ${ }^{13,18,21}$ From a health economy perspective, extra costs generated by VAP are another important outcome and, to our knowledge, have not been adequately studied. The aim of this study was to investigate outcomes attributable to VAP, with an emphasis on morbidity and costs.

\section{METHODS \\ Study Design}

The University of Geneva Hospitals healthcare delivery system includes medical, surgical, pediatric, and neonatal ICUs. The study was conducted in the 18-bed medical ICU, to which 1,400 patients are admitted per year for a mean stay of 4 days. We performed a retrospective matched (1:1) cohort study using prospectively collected surveillance data from October 1995 to November 1997 to compare all patients with VAP (case-patients) with an individually matched cohort of patients receiving mechanical ventilation without pneumonia (control-

Drs. Hugonnet and Pittet are from the Infection Control Program and Drs. Eggimann and Chevrolet are from the Medical Intensive Care Unit, Department of Internal Medicine; and Dr. Borst and Ms. Maricot are from the Medico-economic Unit, Department of Radiology, University of Geneva Hospitals, Geneva, Switzerland.

Address reprint requests to Prof. Didier Pittet, MD, MS, Infection Control Program, Department of Internal Medicine, University of Geneva Hospitals, 1211 Geneva 14, Switzerland.

Supported in part by a research grant provided by the "Comité directeur des Laboratoires de Recherche clinique et Groupe de Recherche en Analyse des Systèmes de Santé du Département de Médecine Interne" of the University of Geneva Hospitals; and a research grant provided by the Swiss National Science Foundation (grant no. 32-68164.02).

The authors thank the members of the Infection Control Program, in particular Nadia Colaizzi for data management and Marie-Noëlle Constantin-Chraiti and Sylvie Touveneau for conducting field surveillance. They also thank Rosemary Sudan for providing editorial assistance. 
patients). Surveillance definitions, diagnostic procedures, and clinical management of patients with pneumonia did not change during the study period. ${ }^{22}$ Patients were discharged from the ICU according to specific guidelines designed for this unit, and compliance with these was checked daily by a senior staff member. Discharge policy did not change during the study period.

\section{Surveillance and Definitions}

We conducted on-site prospective surveillance of all nosocomial infections. ${ }^{22}$ Briefly, one infection control nurse visited the ICU daily (5 days per week) and completed a dedicated surveillance chart for all patients who stayed in the unit for 48 hours or more. Surveillance was continued up to 5 days after ICU discharge to detect infections that were acquired in this setting, but clinically evident only after discharge. ${ }^{23}$ Nosocomial infections were defined according to Centers for Disease Control and Prevention criteria, ${ }^{22,24,25}$ except that asymptomatic bacteriuria was not considered an infection ${ }^{26}$ and the definition of pneumonia was modified as described below.

Information was collected regarding all nosocomial infections, demographic characteristics, admission and discharge diagnoses, exposure to invasive devices, ICU and hospital survival status, and costs.

\section{Estimation of Costs}

The University of Geneva Hospitals has developed a system to compute patient costs to comply with Swiss legal requirements. The model is based on both hospital accounting data and patient activity data extracted from the hospital information system. A total cost for each hospital administrative structure (eg, ICU, radiology department, or microbiology laboratory) is first computed by adding internal costs of the structure itself and imported costs from other hospital structures. Unit costs are then computed for each resource produced by this structure by dividing the total cost by the sum of produced activity. These unit costs are finally redistributed to patients according to their consumed resources, thus providing a precise allocation of total hospital expenditures to real patient costs. As a final result, the sum of all patient costs is absolutely equal to the total hospital care expenditure. This model has been implemented in another Swiss university hospital and has been validated by external auditing offices; it has now also been chosen for use in all Swiss hospitals. Costs were converted from Swiss francs into U.S. dollars using the exchange rate of the middle of the study period (ie, a factor of 1.3 Swiss franc for 1 U.S. dollar).

\section{Case-Patients}

VAP was defined according to modified Centers for Disease Control and Prevention criteria, ${ }^{24,25}$ which are close to those established by the American College of Chest Physicians ${ }^{27}$ and those adopted by the board of directors of the American Thoracic Society. ${ }^{28}$ VAP was diagnosed in a patient receiving mechanical ventilation for 48 hours who presented a clinical suspicion requiring the presence of two of the following: fever (increase of $\geqslant 1^{\circ} \mathrm{C}$ or body temperature $\left.>38.3^{\circ} \mathrm{C}\right)$; leukocytosis $(25 \%$ increase and a value $\geqslant 10,000 \mathrm{~mm}^{3}$ ) or leukopenia $(25 \%$ decrease and a value $\leqslant 5,000 \mathrm{~mm}^{3}$ ); or purulent tracheal secretions ( $>25$ neutrophils per high-powered field). The patient also had to have one of the following: new and persistent infiltrates on chest radiograph (when available, positive cultures, the specimens for which had been obtained from bronchoalveolar lavage $\left[\geqslant 10^{4}\right.$ colony-forming units $/ \mathrm{mL}$, were taken into account to support the diagnosis); the same microorganism isolated from pleural fluid and tracheal secretions, radiographic cavitation, or histopathologic demonstration of pneumonia; or positive cultures, the specimens for which had been obtained from bronchoalveolar lavage. Only the first episode of VAP was considered.

\section{Selection of Control-Patients}

A control-patient was a patient as similar as possible to a case-patient, but without VAP ${ }^{29,30}$ Eligible controlpatients were all patients who benefited from mechanical ventilation for 48 hours or more and who remained free of pneumonia during their entire ICU stay. Case-patients were individually matched with one control-patient on several variables, and a 20-point scale scoring system was determined to ensure optimal matching as follows: total number of discharge diagnoses ${ }^{30,31} \pm 2$ (6 points); duration of mechanical ventilation of the control-patient at least that of the case-patient until pneumonia occurred minus $10 \%$ ( 5 points); age \pm 5 years ( 4 points) or \pm 6 to 10 years (3 points); ICU admission diagnosis according to International Classification of Diseases, 10th edition (3 points); gender (1 point); and study period (admission before or after March 1, 1997) (1 point). All possible pairs were investigated and the best control-patient for each case-patient was retained. If several control-patients had the same score when matched for a particular casepatient, one was randomly selected. If a control-patient was the best for more than one case-patient, then the second best on the list was selected, and this procedure was repeated until each control-patient was used only once. Based on an a priori decision, only pairs with a score of $15 / 20$ or greater were kept for analysis.

\section{Statistical Analysis}

The main measures of interest were the ICU length of stay, duration of mechanical ventilation, costs, and mortality rate. Secondary measures were hospital length of stay, costs, and mortality rate.

Length of stay, duration of mechanical ventilation, and costs were compared among the entire cohort and among pairs in which both the case-patient and the control-patient survived. ${ }^{30}$

Continuous variables were expressed as medians and ranges or interquartile ranges. To respect the matching ${ }^{32}$ attributable length of stay, duration of mechanical ventilation, and costs were expressed as the means of the individual case-control differences. Significance tests 
TABLE 1

Length of Stay and Costs According to Infection Status for the Medical InTEnsive Care Unit, University of Geneva HOSPITALS, 1995 TO $1997^{*}$

\begin{tabular}{lccc}
\hline & No. & Median Length of Stay (d) & Median Costs (U.S. Dollars) \\
\hline Total study population & 1,068 & $5(3-9)$ & $8,228(5,409-14,351)$ \\
Patients without ICU-acquired infection & 787 & $4(2-6)$ & $6,691(4,767-9,759)$ \\
Patients with ICU-acquired infection & 281 & $11(8-18)$ & $19,032(12,759-28,561)$ \\
Patients with ICU-acquired VAP & 106 & $16(11-25)$ & $26,597(18,662-40,756)$ \\
\hline
\end{tabular}

ICU = intensive care unit; VAP = ventilator-associated pneumonia.

${ }^{\star}$ Interquartile ranges appear in parentheses.

were performed using the one-sample Student's $t$ test, and $95 \%$ confidence intervals $\left(\mathrm{CI}_{95}\right)$ based on the $t$ distribution were reported.

The attributable mortality rate of VAP was the difference in case-fatality rate between case-patients and control-patients. We used the McNemar method to test whether the attributable mortality rate differed from zero and built confidence intervals using the normal approximation of the binomial distribution.

All tests were two-tailed, and $P$ values of .05 or less were considered statistically significant. All statistical analyses were conducted with STATA software (version 6.0; STATA Corp., College Station, TX).

\section{RESULTS}

\section{Total Surveyed Population}

During the study period, we surveyed 1,049 patients admitted to the medical ICU for 48 hours or more, accounting for 1,068 patient-stays. The median age was 63 years (range, 16 to 92 years), and the male-tofemale ratio was $1: 4$. The median ICU stay was 5 days (range, 2 to 134 days). Device use was as follows: $88 \%$ of patients had a peripheral catheter, $67 \%$ had a central catheter, $83 \%$ had an arterial catheter, $70 \%$ had a urinary catheter, and $42 \%$ underwent mechanical ventilation. We detected 554 ICU-acquired infections in 281 patients (26.8\%). Leading infections were pneumonia (28.7\%), bloodstream (20.4\%), skin and soft tissue (15.3\%), catheter exit site (13.5\%), and urinary tract (11.2\%). Compared with patients without ICU-acquired infection, patients with any type of ICU-acquired infection and patients with VAP had a median length of stay and costs that were almost 3 times greater and 4 times greater, respectively (Table 1 ).

ICU and hospital mortality rates were $16.8 \%$ and $24.4 \%$, respectively. Most ICU deaths occurred among patients receiving mechanical ventilation $(140[31.0 \%]$ of 452 patients receiving ventilation vs 39 [6.3\%] of 616 patients not receiving ventilation, yielding a relative risk of death of $4.9\left[\mathrm{CI}_{95}, 3.5\right.$ to 6.8$\left.]\right)$.

Overall, 452 patients benefited from mechanical ventilation. Among these, 11 were excluded because the episode of pneumonia occurred before or within 48 hours of the start of ventilatory support. Of 441 patients receiv- ing mechanical ventilation, $106(24 \%)$ developed VAP, resulting in an infection rate of 37.0 per 1,000 ventilationdays $\left(\mathrm{CI}_{95}, 30.6\right.$ to 44.9$)$.

\section{Success of Matching}

The cohort of eligible control-patients consisted of 335 patients who were matched with 106 case-patients. Nine pairs (8.5\%) were excluded due to insufficient matching, leaving 97 pairs for further analysis. All pairs were matched for the number of discharge diagnoses, $92 \%$ for the duration of mechanical ventilation before the onset of VAP in case-patients, $73 \%$ for age \pm 5 years, $92 \%$ for age \pm 10 years, $85 \%$ for admission diagnosis, $85 \%$ for study period, and $71 \%$ for gender. Although pulmonary disease as an admission diagnosis was more frequent among casepatients, this trend did not reach statistical significance $(P=.13)$. The median score was 19 points (range, 15 to 20 points); 26 pairs were perfectly matched. Eighty-seven percent of the variables (508 of 582) were successfully matched.

Of 97 episodes of VAP, 69 (71\%) were diagnosed through quantitative or semiquantitative culture techniques. Seventeen episodes were polymicrobial. The leading pathogens were gram-negative microorganisms (54\%), mainly Pseudomonas aeruginosa (12\%), Enterobacter species (9\%), Haemophilus influenzae (7\%), and Escherichia coli $(6 \%)$. Staphylococcus aureus accounted for $10 \%$ of the pathogens identified.

Case-patients and control-patients did not differ in terms of the matching variables and nosocomial infections, other than VAP (Table 2). Hospital stay before ICU admission and ICU stay before initiation of mechanical ventilation were similar in the two groups. The total duration of mechanical ventilation was significantly greater among the case-patients.

In Table 2, control-patients selected by the matching process are compared with the remaining eligible control-patients. Illness tended to be more severe among selected control-patients as the number of discharge diagnoses, duration of mechanical ventilation, ICU stay, and proportion of other ICU-acquired infections were all greater. The median ICU length of stay was 10 days (interquartile range, 7 to 14 days) and 4 days (interquar- 
TABLE 2

Selected Characteristics of the Study Population From the Medical Intensive Care Unit, University of Geneva Hospitals, 1995 TO $1997^{*}$

\begin{tabular}{|c|c|c|c|c|c|}
\hline Characteristic & $\begin{array}{c}\text { Case-Patlents } \\
(\mathbf{N}=97)\end{array}$ & $\begin{array}{l}\text { Selected Control- } \\
\text { Patlents (N = 97) }\end{array}$ & $\boldsymbol{P}$ & $\begin{array}{l}\text { Eligible Control- } \\
\text { Patients ( } \mathbf{N}=\mathbf{2 3 8} \text { ) }\end{array}$ & $\boldsymbol{p}$ \\
\hline \multicolumn{6}{|l|}{ Matching variables } \\
\hline No. of discharge diagnoses & $6(4-8)$ & $6(5-8)$ & .38 & $5(3-6)$ & $<.001$ \\
\hline No. of ventilation-days at risk & $7(4-9)$ & $7(4-10)$ & .43 & $2(1-3)$ & $<.001$ \\
\hline Age, y & $65.6(55.3-72.2)$ & $63.1(51.6-71.3)$ & .22 & $59.3(41.4-72.7)$ & .23 \\
\hline Admission diagnosis, no. (\%) & & & .08 & & .001 \\
\hline Cardiovascular disease & $19(19.6)$ & $17(17.5)$ & & $34(14.3)$ & \\
\hline Infectious disease & $49(50.5)$ & $57(58.8)$ & & $101(42.4)$ & \\
\hline Pulmonary disease & $16(16.5)$ & $11(11.3)$ & & $24(10.1)$ & \\
\hline Other disease & $13(13.4)$ & $12(12.4)$ & & $79(33.2)$ & \\
\hline Period, no. (\%) & & & 1.00 & & .77 \\
\hline Before March 1, 1997 & $67(69.1)$ & $66(68.0)$ & & $158(66.4)$ & \\
\hline After March 1, 1997 & $30(31.0)$ & $31(32.0)$ & & $80(33.6)$ & \\
\hline Gender, no. (\%) & & & .34 & & .41 \\
\hline Male & $63(65.0)$ & $57(58.8)$ & & $128(53.8)$ & \\
\hline Female & $34(35.0)$ & $40(41.2)$ & & $110(46.2)$ & \\
\hline \multicolumn{6}{|l|}{ Other variables } \\
\hline Hospital stay before ICU admission, d & $0(0-1)$ & $0(0-1)$ & .27 & $0(0-1)$ & .59 \\
\hline ICU stay before mechanical ventilation, $\mathrm{d}$ & $0(0-1)$ & $0(0-0)$ & .49 & $0(0-0)$ & .015 \\
\hline Total duration of mechanical ventilation, $\mathrm{d}$ & $10(6-16)$ & $7(4-10)$ & $<.001$ & $2(1-3)$ & $<.001$ \\
\hline \multicolumn{6}{|l|}{ ICU-acquired infections, no. (\%) } \\
\hline Primary bloodstream infection & $23(23.7)$ & $29(29.9)$ & .38 & $14(5.9)$ & $<.001$ \\
\hline Catheter exit-site infection & $9(9.3)$ & $14(14.4)$ & .36 & $6(2.5)$ & $<.001$ \\
\hline Urinary tract infection & $14(14.4)$ & $10(10.3)$ & .48 & $8(3.4)$ & .011 \\
\hline Other nosocomial infection & $35(36.1)$ & $24(24.7)$ & .098 & $14(5.9)$ & $<.001$ \\
\hline Any nosocomial infection other than VAP & $55(56.7)$ & $47(48.5)$ & .24 & $37(15.6)$ & $<.001$ \\
\hline
\end{tabular}

ICU $=$ intensive care unit; VAP $=$ ventilator-associated pneumonia

*Continuous variables are summarized as medians (interquartile ranges). All $P$ values are two-tailed.

$t P$ values are for the comparison between case-patients and selected control-patients.

${ }^{\ddagger} P$ values are for the comparison between selected control-patients and eligible control-patients.

tile range, 3 to 6 days) among control-patients and non-selected control-patients, respectively $(P<.001)$.

\section{Invasive Devices and Antibiotics}

The median duration of exposure among controlpatients and case-patients before the onset of VAP was 9 and 7 days for central venous catheters $(P=.059), 8$ and 8 days for arterial catheters $(P=.30), 8$ and 7 days for urinary catheters $(P=.50)$, and 8 and 7 days for antibiotics $(P=.01)$, respectively. When the same exposures were compared between control-patients and case-patients during the entire ICU stay, all were greater among case-patients: 9 and 14 days for central venous catheters, 8 and 13 days for arterial catheters, 8 and 13 for urinary catheters, and 8 and 13 for antibiotics, respectively (all $P$ values $<.001$ ).

\section{ICU Length of Stay, Costs, and Mortality}

ICU length of stay and duration of mechanical ventilation were significantly greater among case-patients (Table 3).
The median costs were $\$ 20,941$ (interquartile range, $\$ 15,273$ to $\$ 32,947$ ) among the total population and were significantly higher among case-patients, resulting in mean attributable costs of $\$ 10,450\left(\mathrm{CI}_{95}, \$ 5,521\right.$ to $\$ 15,380$ ) per episode of VAP (Table 3), totaling $\$ 1,107,700$ when considering all 106 episodes of VAP that occurred during the study period. The distribution of costs stratified by infection status according to the main categories is shown in the figure.

The ICU mortality rate was $28.4 \%$ (55 of 194). The case-fatality rate among case-patients and control-patients was $32.0 \%$ and $24.7 \%$, respectively, resulting in an attributable mortality rate of $7.3 \%\left(\mathrm{CI}_{95},-6.4 \%\right.$ to $\left.20.8 \%\right)$ and a relative risk of death of $1.3\left(\mathrm{CI}_{95}, 0.8\right.$ to 2.0$)$.

\section{Hospital Length of Stay, Costs, and Mortality}

The median hospital length of stay among casepatients and control-patients was 33.5 days (interquartile range, 18.5 to 59 days) and 23.5 days (interquartile range, 15 to 43 days), respectively, yielding a mean attributable 
TABLE 3

Length of Stay in the Intensive Care Unit, Duration of Mechanical Ventilation, and Costs Attributable to Ventid.atorAssociated Pneumonia in the Medical InTEnsive Care Unit, UnIVerstiy of Geneva Hospitals, 1995 to $1997^{*}$

\begin{tabular}{|c|c|c|c|c|}
\hline & No. of Pairs & Case-Patlents* & Control-Patients* & Attrlbutable to $\operatorname{VAP}^{\dagger}\left(\mathrm{Cl}_{9 \mathrm{~B}}\right)$ \\
\hline \multicolumn{5}{|l|}{ Length of stay, $\mathrm{d}$} \\
\hline Total population & 97 & $15(11-24)$ & $10(7-14)$ & $7.2(4.1-10.4)$ \\
\hline Survivors & 50 & $15.5(10-24)$ & $11(8-14)$ & $5.9(2.8-9.1)$ \\
\hline \multicolumn{5}{|c|}{$\begin{array}{l}\text { Duration of mechanical } \\
\text { ventilation, } d\end{array}$} \\
\hline Total population & 97 & $10(6-16)$ & $7(4-10)$ & $5.1(2.2-8.0)$ \\
\hline Survivors & 50 & $11(6-17)$ & $7.5(4-10)$ & $4.3(1.5-7.1)$ \\
\hline \multicolumn{5}{|l|}{ Costs, U.S. dollars } \\
\hline Total population & 96 & $24,727(18,348-39,703)$ & $17,438(12,261-24,226)$ & $10,450(5,521-15,380)$ \\
\hline Survivors & 49 & $26,015(18,428-37,315)$ & $18,498(13,900-24,755)$ & $7,925(1,563-14,287)$ \\
\hline
\end{tabular}

VAP $=$ ventilator-associated pneumonia; $\mathrm{CI}_{95}=95 \%$ confidence interval.

*Summary measures are medians (interquartile ranges).

†Summary measures are means of the difference between case-patients and control-patients.

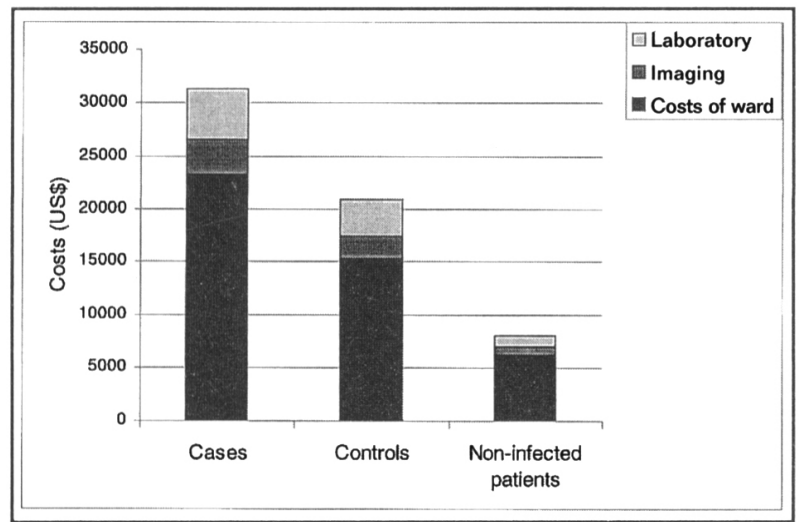

FIGURE. Costs among patients with ventilator-associated pneumonia (cases), closely matched control-patients without pneumonia (controls), and patients who remained free of any intensive care unit-acquired infection (non-infected patients). Mean costs include costs of the ward (physicians and nurses), laboratory, and imaging. Costs are total costs and include overheads.

extra length of stay of 10.0 days $(P=.06)$. Hospital costs among case-patients were higher than those among control-patients by a mean excess of $\$ 15,986$. The in-hospital case-fatality rate was similar in case-patients and controlpatients $(37.1$ vs $38.1 \% ; P=1.00)$.

\section{DISCUSSION}

Healthcare-associated infections in the ICU dramatically affect morbidity and the use of hospital resources. Our study showed that patients with any nosocomial infection and those with VAP had an ICU stay that was 3 and 4 times longer, respectively, than that of patients without nosocomial infection. Extra costs were also generated in the same proportions.

Patients receiving mechanical ventilation represent a large proportion of ICU patients, more than $40 \%$ in the current study, which was similar to other reports. $3,20,33$ They are at high risk of nosocomial pneumonia, as well as death, and we showed that most of the ICU deaths occurred in this group of patients. Investigating outcomes of VAP using a matched cohort study design makes casepatients and control-patients relatively similar apart from the presence of VAP so that differences in terms of morbidity, costs, and mortality can be attributed to the infection, provided that the selected matching variables adequately control for confounding. We found that VAP was associated with a significant excess of ICU length of stay and costs and a trend toward a higher case-fatality rate.

To our knowledge, 11 published matched cohort studies have investigated outcome attributable to VAP. ${ }^{13,16,18,21,34-40}$ Two are difficult to interpret because of insufficient matching ${ }^{38}$ or inclusion of nosocomial pneumonia other than VAP, ${ }^{37}$ and one was presented in abstract form only. 39

Length of stay is a recognized surrogate marker of patient morbidity. It provides a good estimate of the burden on hospital resources, is not dependent on the accounting system or differences between countries, and is consequently widely used for comparison purposes. Whereas extra costs attributable to VAP estimate the direct economic loss, extra length of stay gives more insight into the impact of VAP on workload and loss of new admissions due to beds occupied by infected patients. ${ }^{31}$ We found that the mean ICU and hospital extra length of stay was 7.2 and 10.0 days, respectively. There is homogeneity of the results in most studies in the literature, as the median ICU extra stay ranged from 5 to 6 days. ${ }^{13,16,21,34,36}$ Hospital extra stay is also consistent across studies, ranging from 9 to 11.5 days. ${ }^{13,18,21,34}$ In our study, control-patients were tightly matched on the number of days of mechanical ventilation before the onset of pneumonia, making the estimate of the extra days of mechanical ventilation of great value. Prolongation of mechanical 
ventilation was 5.1 days, similar to results reported in other studies that used the same matching variables. $13,21,39$ Regardless of the matching procedure, case definition, patient profile, or microorganism involved, it appears clearly that VAP negatively affects patient morbidity. Consequently, we believe that there is enough evidence to support these findings and that the increased morbidity should be sufficient to stimulate prevention efforts. ${ }^{41,42}$

At a time of cost containment, estimating the financial burden of nosocomial infection is a pivotal tool for infection control practitioners to compete for resources. However, cost estimation is not a straightforward exercise and some caveats may be difficult to avoid. ${ }^{31,43-45}$ Because of cost shifting between items and departments, charges do not equal costs (charges are usually larger). Costs represent a more reliable estimate of the financial burden and should be preferred to charges. ${ }^{31}$ To our knowledge, only four studies with a similar design have estimated costs attributed to VAP. ICU extra costs per episode were obtained by multiplying the number of ICU extra days by the mean costs per day in the ICU and reached $\$ 8,800^{36}$ and $\$ 7,750 .{ }^{21}$ With the use of hospital charges, extra costs reached $\$ 40,000$ per episode in two other studies. ${ }^{18,34}$ The methodology we used to assess the financial burden of VAP differs from those used by previous studies and can be considered as the gold standard. ${ }^{31,43,46,47}$ First, our method is close to microcosting techniques, in which a complete list of all care items and services is used. This list allows for computing the total cost of each item and each patient, knowing the precise resource consumption of each patient. Our approach was possible due to the availability of online and daily updated data generated by the hospital information system. ${ }^{48,49}$ Second, we used costs instead of charges, which are a more accurate measure, independent of cost shifting. ${ }^{31,43}$ We found that total hospital costs attributable to VAP were more than $\$ 15,000$, with most of this amount being used while the patient was in the ICU. A recently published study found a similar figure, as the hospital cost attributed to VAP was estimated by multiple linear regression to be approximately $\$ 12,000 .^{50}$

The case-fatality rate among patients with VAP ranges from $23 \%$ to $70 \%, 11,13,16$ but the extent to which VAP contributes to death remains controversial. Four matched cohort studies showed that VAP had a significant attributable mortality rate, ranging from $13.5 \%$ to $27.1 \%,{ }_{16,35,39,40}$ but four others failed to demonstrate such an effect. ${ }^{13,18,21,34}$ In the current study, the case-fatality rate among case-patients was $32.0 \%$ and the attributable mortality rate was $7.3 \%$. A reason why we were unable to show a significant difference in mortality may relate to the fact that matching on surrogates of severity of illness may have correctly controlled for the severity bias that falsely attributed ICU mortality to VAP in several of the previous studies. Another reason may be that our study was underpowered to detect a difference, which was the case with all of these studies except one. ${ }^{18}$

Our study has some limitations. We used surveil- lance definitions that include both clinical signs and symptoms and results of invasive diagnostic procedures to define VAP, which is neither sensitive nor specific. ${ }^{51,52}$ Minei et al. illustrated, in a cohort of surgical ICU patients, that different definitions of VAP greatly affected the infection rate, showed little concordance between them, and identified different patients and, consequently, that risk factors for meeting one definition or the other were different. ${ }^{53}$ Predicting the direction of the bias resulting from this misclassification would be hazardous; however, the use of invasive diagnostic procedures did not add a prognostic value to the suspicion of VAP based on clinical criteria. ${ }^{54}$ Clearly, all studies dealing with VAP are to some extent limited by the issue of the case definition, and this calls for further research.

The best estimate of the attributable outcome requires that the matching process remove the effect of confounding factors. However, the ideal matching variables are a subject of debate, raising the issue of insufficient matching or over-matching. Unlike several matched cohort studies, ${ }^{13,16,18,21,40}$ our study did not match on a severity score such as the Acute Physiology and Chronic Health Evaluation, but achieved a close match on the number of days of mechanical ventilation before the onset of VAP and the number of discharge diagnoses, as suggested by Haley. ${ }^{31}$ Matching on a severity score recorded at admission poses two problems. First, it predicts mortality and may thus result in over-matching. Second, it does not take into account what happens between admission and onset of VAP. Matching on the number of ventilation-days provides a more dynamic measure and accounts for changes in the patient's condition over time. Haley showed that the number of discharge diagnoses was a true confounder because it was associated with both nosocomial infections and length of stay and $\operatorname{costs}^{31}$ and that it can be used to account for severity of illness. Selected control-patients were extremely ill, more ill than the eligible control-patients who were finally not selected, and probably just as ill as the case-patients before the onset of VAP (Table 2). Furthermore, close matching also ensured that case-patients and control-patients experienced the same frequency of primary bloodstream infection, which is associated with high mortality and morbidity. ${ }^{30}$ Therefore, our matching procedure met its objective to render case-patients and control-patients as similar as possible apart from the presence of VAP.

Infections acquired in the ICU account for a disproportional high consumption of resources and negatively affect patient morbidity. In particular, the significant burden of VAP justifies the implementation of specific preventive strategies and the need for further research with the ultimate objective of improving patient safety.

\section{REFERENCES}

1. Kohn L, Corrigan J, Donaldson M. To Err Is Human: Building a Safer Health System. Washington, DC: Institute of Medicine; 1999.

2. Public health focus: surveillance, prevention, and control of nosocomial infections. MMWR 1992;41:783-787.

3. Vincent JL, Bihari DJ, Suter PM, et al. The prevalence of nosocomial infection in intensive care units in Europe: results of the European 
Prevalence of Infection in Intensive Care (EPIC) Study. JAMA 1995;274:639-644.

4. Cook D. Ventilator associated pneumonia: perspectives on the burden of illness. Intensive Care Med 2000;26(suppl 1):S31-S37.

5. Centers for Disease Control and Prevention NNIS System. National Nosocomial Infections Surveillance (NNIS) System reports: data summary from January 1992-April 2000, issued June 2000. Am J Infect Control 2000;28:429-448.

6. Cook DJ, Walter SD, Cook RJ, et al. Incidence of and risk factors for ventilator-associated pneumonia in critically ill patients. Ann Intern Med 1998;129:433-440.

7. Finkelstein R, Rabino G, Kassis I, Mahamid I. Device-associated, device-day infection rates in an Israeli adult general intensive care unit. I Hosp Infect 2000:44:200-205.

8. Wallace WC, Cinat M, Gornick WB, Lekawa ME, Wilson SE. Nosocomial infections in the surgical intensive care unit: a difference between trauma and surgical patients. Am Surg 1999;65:987-990.

9. Richards MJ, Edwards JR, Culver DH, Gaynes RP. Nosocomial infections in combined medical-surgical intensive care units in the United States. Infect Control Hosp Epidemiol 2000;21:510-515.

10. Esteban A, Anzueto A, Frutos F, et al. Characteristics and outcomes in adult patients receiving mechanical ventilation: a 28-day international study. JAMA 2002;287:345-355.

11. Fagon JY, Chastre J, Domart Y, et al. Nosocomial pneumonia in patients receiving continuous mechanical ventilation: prospective analysis of 52 episodes with use of a protected specimen brush and quantitative culture techniques. Am Rev Respir Dis 1989:139:877-884.

12. Fagon JY, Chastre J, Vuagnat A, Trouillet JL, Novara A, Gibert C. Nosocomial pneumonia and mortality among patients in intensive care units. JAMA 1996;275:866-869.

13. Heyland DK, Cook DJ, Griffith L, Keenan SP, Brun-Buisson C. The attributable morbidity and mortality of ventilator-associated pneumonia in the critically ill patient: the Canadian Critical Trials Group. Am I Respir Crit Care Med 1999;159:1249-1256.

14. Kollef MH. Ventilator-associated pneumonia. JAMA 1993;270:19651970.

15. Rello J, Quintana E, Ausina V, et al. Incidence, etiology, and outcome of nosocomial pneumonia in mechanically ventilated patients. Chest 1991:100:439-444.

16. Fagon JY, Chastre J, Hance AJ, Montravers P, Novara A, Gibert C. Nosocomial pneumonia in ventilated patients: a cohort study evaluating attributable mortality and hospital stay. Am J Med 1993:94:281-288.

17. Ibrahim EH, Ward S, Sherman G, Kollef MH. A comparative analysis of patients with early-onset vs late-onset nosocomial pneumonia in the ICU setting. Chest 2000;117:1434-1442.

18. Rello J, Ollendorf DA, Oster G, et al. Epidemiology and outcomes of ventilator-associated pneumonia in a large US database. Chest 2002 ; 122:2115-2121.

19. Craven DE, Kunches LM, Lichtenberg DA. Nosocomial infection and fatality in medical surgical intensive care unit patients. Arch Intern Med 1988;148:1161-1168.

20. Ibrahim EH, Tracy L, Hill C, Fraser VJ, Kollef MH. The occurrence of ventilator-associated pneumonia in a community hospital: risk factors and clinical outcomes. Chest 2001;120:555-561.

21. Papazian L, Bregeon F, Thirion X, et al. Effect of ventilator-associated pneumonia on mortality and morbidity. Am J Respir Crit Care Med 1996:154:91-97

22. Eggimann P, Harbarth S, Constantin MN, Touveneau S, Chevrolet JC Pittet D. Impact of a prevention strategy targeted at vascular-access care on incidence of infections acquired in intensive care. Lancet 2000;355:1864-1868.

23. Hugonnet S, Eggimann P, Sax H, Touveneau S, Chevrolet J-C, Pittet D. ICU-acquired infections: is post-discharge surveillance useful? Crit Care Med 2002;30:2636-2638.

24. Garner JS, Jarvis WR, Emori TG, Horan TC, Hughes JM. CDC definitions for nosocomial infections. Am J Infect Control 1988;16:128-140.

25. Centers for Disease Control. CDC definitions for nosocomial infections, 1988. Am Rev Respir Dis 1989;139:1058-1059.

26. Pittet D, Harbarth S, Ruef C, et al. Prevalence and risk factors for nosocomial infections in four university hospitals in Switzerland. Infect Control Hosp Epidemiol 1999;20:37-42.

27. Meduri GU, Johanson WG Jr. International consensus conference: clinical investigation of ventilator-associated pneumonia. Introduction. Chest 1992;102(suppl 1):S551-S552.

28. Hospital-acquired pneumonia in adults: diagnosis, assessment of severity, initial antimicrobial therapy, and preventive strategies. A consensus statement, American Thoracic Society, November 1995. Am J
Respir Crit Care Med 1996;153:1711-1725.

29. Martin MA, Pfaller MA, Wenzel RP. Coagulase-negative staphylococcal bacteremia: mortality and hospital stay. Ann Intern Med 1989;110:9-16.

30. Pittet D, Tarara D, Wenzel RP Nosocomial bloodstream infection in critically ill patients: excess length of stay, extra costs, and attributable mortality. JAMA 1994;271:1598-1601.

31. Haley RW. Measuring the costs of nosocomial infections: methods for estimating economic burden on the hospital. Am J Med 1991:91(suppl $3 \mathrm{~B}): \mathrm{S} 32-\mathrm{S} 38$

32. Haley RW, Schaberg DR, Von Allmen SD, McGowan JE Jr. Estimating the extra charges and prolongation of hospitalization due to nosocomial infections: a comparison of methods. J Infect Dis 1980;141:248-257.

33. National Nosocomial Infections Surveillance (NNIS) System. National Nosocomial Infections Surveillance (NNIS) System report: data summary from January 1992-June 2001, issued August 2001. Am J Infect Control 2001;29:404-421.

34. Baker AM, Meredith JW, Haponik EF. Pneumonia in intubated trauma patients: microbiology and outcomes. Am J Respir Crit Care Med 1996; 153:343-349.

35. Bercault N, Boulain T. Mortality rate attributable to ventilator-associated nosocomial pneumonia in an adult intensive care unit: a prospective case-control study. Crit Care Med 2001;29:2303-2309.

36. Kappstein I, Schulgen G, Beyer U, Geiger K, Schumacher M Daschner FD. Prolongation of hospital stay and extra costs due to ventilator-associated pneumonia in an intensive care unit. Eur J Clin Microbiol Infect Dis 1992;11:504-508.

37. Craig CP, Connelly S. Effect of intensive care unit nosocomial pneumonia on duration of stay and mortality. Am J Infect Control 1984;12 233-238.

38. Cunnion KM, Weber DJ, Broadhead WE, Hanson LC, Pieper CF Rutala WA. Risk factors for nosocomial pneumonia: comparing adult critical-care populations. Am J Respir Crit Care Med 1996;153:158162.

39. Devos N, Pinsard M, Rigaud JP, Berthelot G, Canonne M. Morbidité et mortalité des pneumopathies acquises sous ventilation mécanique (PAVM). Réanimation 2001;10(suppl 1):S158.

40. Rello J, Jubert P, Valles J, Artigas A, Rue M, Niederman MS. Evaluation of outcome for intubated patients with pneumonia due to Pseudomonas aeruginosa. Clin Infect Dis 1996;23:973-978.

41. Eggimann P, Pittet D. Infection control in the ICU. Chest 2001;120: 2059-2093.

2. Kollef MH. The prevention of ventilator-associated pneumonia. $N$ Engl JMed 1999;340:627-634.

43. Finkler SA. The distinction between cost and charges. Ann Intern Med 1982:96:102-109

44. Stone PW, Larson E, Kawar LN. A systematic audit of economic evidence linking nosocomial infections and infection control interventions: 1990-2000. Am I Infect Control 2002;30:145-152.

45. Graves N. Economics and preventing hospital-acquired infection. Emerg Infect Dis 2004;10:561-566.

46. Russell LB, Gold MR, Siegel JE, Daniels N, Weinstein MC The role of cost-effectiveness analysis in health and medicine: panel on cost-effectiveness in health and medicine. JAMA 1996;276:1172-1177.

47. Weinstein MC, Siegel JE, Gold MR, Kamlet MS, Russell LB Recommendations of the Panel on Cost-effectiveness in Health and Medicine. JAMA 1996;276:1253-1258.

48. Borst F, Appel R, Baud R, et al. Happy Birthday DIOGENE: a hospital information system born 20 years ago. Int I Med Inf 1999:54:157-167.

49. Borst F, Maricot P. An intranet visualization of costs per AP-DRGs in a Swiss teaching hospital. In: Hofdijk J, Bouwes-Westrup $\mathrm{H}$, de Langen $\mathrm{ZJ}$, eds. Proceedings of the 16th PCS/E International Working Conference, 24 September 2000, Groningen, The Netherlands. 2000:35.

50. Warren DK, Shukla SJ, Olsen MA, et al. Outcome and attributable cost of ventilator-associated pneumonia among intensive care unit patients in a suburban medical center. Crit Care Med 2003;31:1312-1317.

51. Fagon J-Y, Chastre J, Wolff $M$, et al. Invasive and noninvasive strategies for management of suspected ventilator-associated pneumonia: a randomized trial. Ann Intern Med 2000;132:621-630.

52. Pittet D, Bonten MJ. Towards invasive diagnostic techniques as standard management of ventilator-associated pneumonia. Lancet 2000; $356: 874$.

53. Minei JP, Hawkins K, Moody B, et al. Alternative case definitions of ventilator-associated pneumonia identify different patients in a surgical intensive care unit. Shock 2000;14:331-336.

54. Timsit JF, Chevret S, Valcke J, et al. Mortality of nosocomial pneumonia in ventilated patients: influence of diagnostic tools. Am J Respir Crit Care Med 1996;154:116-123. 